\title{
Surgical Management of the Spinal Nerve in Modified Radical Neck Dissection
}

\author{
Attilio Carlo Salgarelli and Pierantonio Bellini \\ Unit of Maxillofacial Surgery \\ Head and Neck Surgery Department \\ University of Modena and Reggio Emilia \\ Italy
}

\section{Introduction}

In 1906, Crile (1906) first reported radical neck dissection as a surgical technique for the treatment of neck lymph-node metastasis of head and neck cancer. It began to be used more widely after the report of Martin et al. (1951). The basic technique for neck dissection involves excising the neck lymphatic tissue, together with the accessory nerve, sternocleidomastoid muscle, and internal jugular vein, although this results in marked postoperative morphological and functional disorders. In particular, severing the accessory nerve is associated with postoperative shoulder dysfunction.

Various techniques for functional (conservative) neck dissection have been introduced to prevent such dysfunction, and these techniques have been modified in various ways (Bocca \& Pignataro, 1967; Bocca et al., 1980; Eisele et al., 1991; Medina \& Lorè, 2005; Suarez, 1963).

The original approach to functional neck dissection was reported by Osvaldo Suarez in 1963. Unlike radical neck dissection, functional neck dissection can prevent postoperative morphological and functional disorders by preserving the accessory nerve, sternocleidomastoid muscle, and internal jugular vein.

Over the past 40 years, there has been ongoing development of various nerve-, vein-, and muscle-preserving techniques. The most recent development is selective neck dissection, based on site-specific lymph drainage patterns. These conservative procedures have attempted to alleviate neck and shoulder morbidity and to ensure that oncological safety is not compromised (Bocca \& Pignataro, 1967; Bocca, 1975; Bocca et al., 1980; Eisele et al., 1991; Medina \& Lorè, 2005; Suarez, 1963).

Damage to the spinal accessory nerve generally leads to the condition known as "sloping shoulder syndrome" (Salgarelli et al., 2009), which consists of:

- numbness over the angle of the jaw and around the ear due to the associated injury to the transverse cervical and great auricular nerves;

- paralysis of the trapezius muscle, resulting in shoulder droop and difficulty in shoulder movement, especially abduction, although some patients retain almost full movement;

- pain, often the worst consequence of injury, resulting from traction of the unsupported shoulder on the brachial plexus or even a sensory element in the spinal accessory nerve;

- winging of the scapula, which occurs because trapezius paralysis allows the medial border of the scapula to lift off the chest wall. 
Shoulder and neck pain associated with neck dissection are well recognized and are closely related to the quality of life of patients undergoing surgical treatment for head and neck cancer. Shoulder pain and dysfunction have been reduced using modified radical neck dissection that preserves cranial nerve XI. Radical neck dissection has been reported to cause greater pain and shoulder dysfunction than conservative procedures.

\section{Anatomy}

The spinal root of the accessory nerve arises from a column of motor neurons called the spinal nucleus, located in the lateral part of the grey matter of the cervical region of the spinal cord. Its filaments arise from segments C1-C6 and emerge to form a trunk, then ascend through the foramen magnum with the vagus nerve to enter the posterior fossa. They join briefly with the cranial root, whose origins lie in the posterolateral groove of the medulla, to form a single trunk, which leaves the base of the skull via the jugular foramen to reach the retrostyloid space. The common trunk terminates here in the cranial and spinal roots, the former joining the superior ganglion of the vagus nerve and the latter passing obliquely downward and laterally either anterior or posterior to the internal jugular vein, or rarely through it. The point where the nerve crosses the jugular vein can be identified by locating the transverse process of the atlas.

Comparative anatomic studies show that the cranial nerve root connections of the spinal accessory nerve are variable, and may be intra- or extracranial (Kaji et al., 2001; Symes \& Ellis, 2005; Younossi-Hartenstein et al., 2001). This can result in differing composition of the nerve, which may in part explain why different impairments can occur in different patients when nerves in the same location are cut. Variation has been documented in both the course of the nerve in the posterior triangle and in its distribution and branches (Caliot et al., 1989; Krause et al., 1991; Soo et al., 1986).

After crossing the internal jugular vein, the accessory nerve descends obliquely downward and backward to the upper part of the sternocleidomastoid muscle. It gives off a branch into the deep surface of this muscle and passes downward and backward, either deep to the sternocleidomastoid muscle or through it, to course across the posterior triangle. The nerve leaves the sternocleidomastoid muscle 0-3.8 (average 1.53) $\mathrm{cm}$ above Erb's point (Salgarelli et al., 2009).

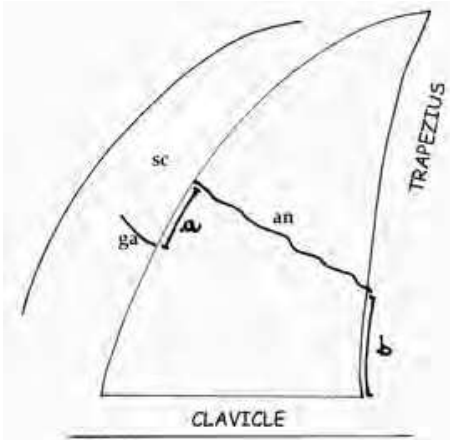

Fig. 1. (ga): great auricular nerve; (sc): sternocleidomastoideo muscle; (an): spinal accessory nerve; (a): distance between great auricular nerve and spinal nerve; (b): distance between clavicle and spinal nerve at the entrance of the trapezius muscle. 
At Erb's point, the bundle of sensory nerves from the cervical plexus emerges from the posterior border of the sternocleidomastoid muscle (Aramrattana et al., 2005; Leung et al., 2004; Salgarelli et al., 2009), midway between the mastoid process and clavicle. Erb's point lies two finger-widths above the clavicle and one finger-width from the posterior border of the sternocleidomastoid muscle. At the great auricular point, the four branches (great auricular, lesser occipital, transverse cervical, and suprascapular) of the cervical plexus exit from the posterior border of the sternocleidomastoid muscle. In many surgical textbooks and in the recent literature, Erb's point has become synonymous with the great auricular point. In the posterior triangle, the nerve runs superficially, reaching the anterior border of the trapezius 2.5-7.3 (average 4.8) cm above the clavicle (Salgarelli et al., 2009).

Like the great auricular nerve, the spinal accessory nerve is often sandwiched tightly between the skin and muscle fascia, and the nerve can be injured when attempting to free up the skin in the lower lateral neck.

\section{Identification of the spinal accessory nerve}

From an oncological perspective, preservation of the spinal accessory nerve in modified neck dissections or lymph node biopsy is, when possible, the first objective in preserving shoulder function. To avoid iatrogenic injury, it is important to identify the course of the accessory spinal during the dissection.

The spinal accessory nerve must be identified as it enters the sternocleidomastoid muscle (anterior identification) if level 5 is not included in the neck dissection and at Erb's point (posterior identification) if level 5 is included in the neck dissection.

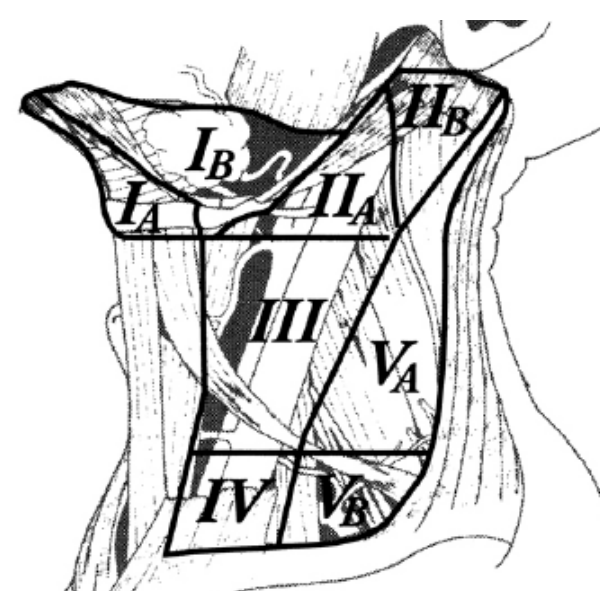

Fig. 2. Current limph node levels.

IA-submental limph nodes; IB-submandibular limph nodes; IIA-limph nodes located anterior to the vertical plane defined by the spinal accessory nerve; IIB- limph nodes located posterior to the vertical plane defined by the spinal accessory nerve; III-limph nodes located around the middle third of the internal jugular vein; IV-limph nodes located around the lower third of the internal jugular vein; VA-limph nodes located in the posterior triangle above the horizontal plane defined by the inferior border of the cricoid cartilage; VB- limph nodes located below the horizontal plane defined by the inferior border of the cricoid cartilage. 
The literature describes myriad incisions for neck dissection (Bocca \& Pignataro, 1967; Bocca et al., 1980; Holmes, 2008; Kademani \& Dierks, 2005; Macfee, 1960; Medina \& Lorè, 2005; Suarez, 1963). The choice of incision design in modified radical neck dissection is guided by the need to access the cervical lymphatic nodes at levels 1-5.

\subsection{Anterior identification of the spinal accessory nerve}

After the skin incision, a flap in the subplatysmal plain above the superficial layer of the deep cervical fascia is elevated to the level of the inferior border of the mandible.

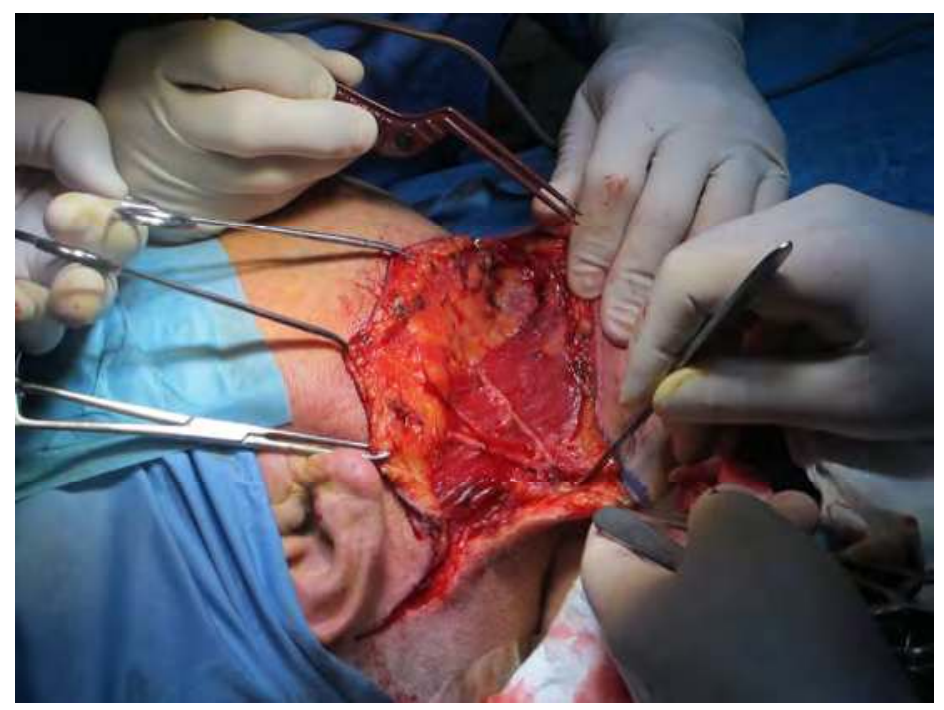

Fig. 3. Elevation of subplatismal flaps on the right side of the neck.

The external jugular vein serves as an excellent guide to keep this dissection at the appropriate level because the dissection should be superficial to it. An incision is then made through the fascia of the sternocleidomastoid muscle and this is elevated around the edge and onto the medial surface. The surgeon must be extremely careful in the upper half of this region, where the spinal accessory nerve enters the muscle. One or more small vessels usually accompany the spinal accessory nerve, which often divides before entering the muscle. The vessels should be cauterized without injuring the nerve, and all branches of the nerve must be preserved to obtain the best shoulder function.

After all of the small vessels entering the sternocleidomastoid muscle have been cauterized, the dissection continues posteriorly along the entire length of the muscle. The internal jugular vein can now be seen through the fascia of the carotid sheath. The dissection is carried upward to the level of the posterior belly of the digastric muscle.

The surgeon now moves to the upper part of the surgical field to complete the identification of the spinal accessory nerve; to approach this area, the sternocleidomastoid muscle is retracted posteriorly and the posterior belly of the digastric muscle is pulled superiorly with a smooth blade retractor, so the nerve is dissected toward the carotid sheath. 


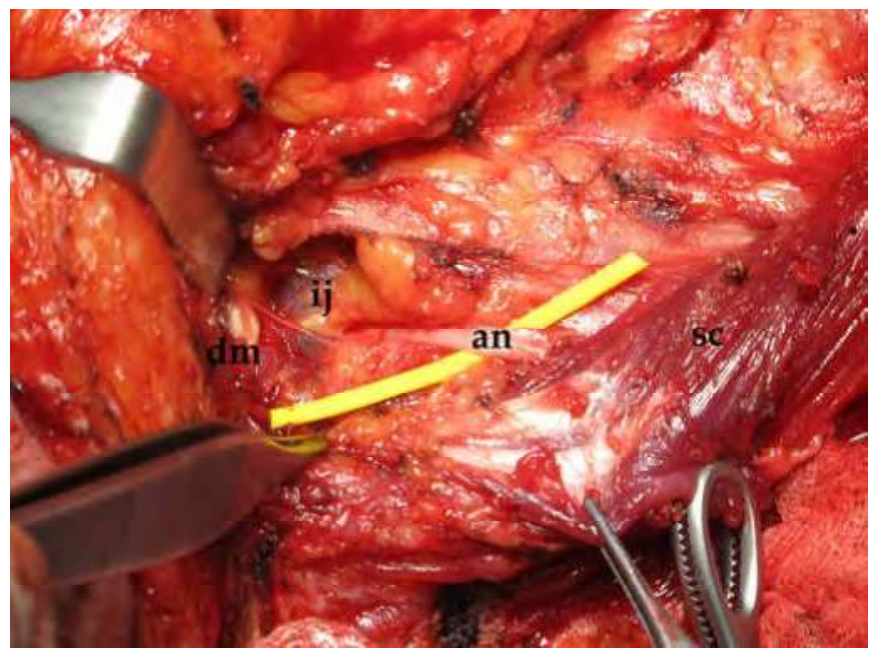

(a)

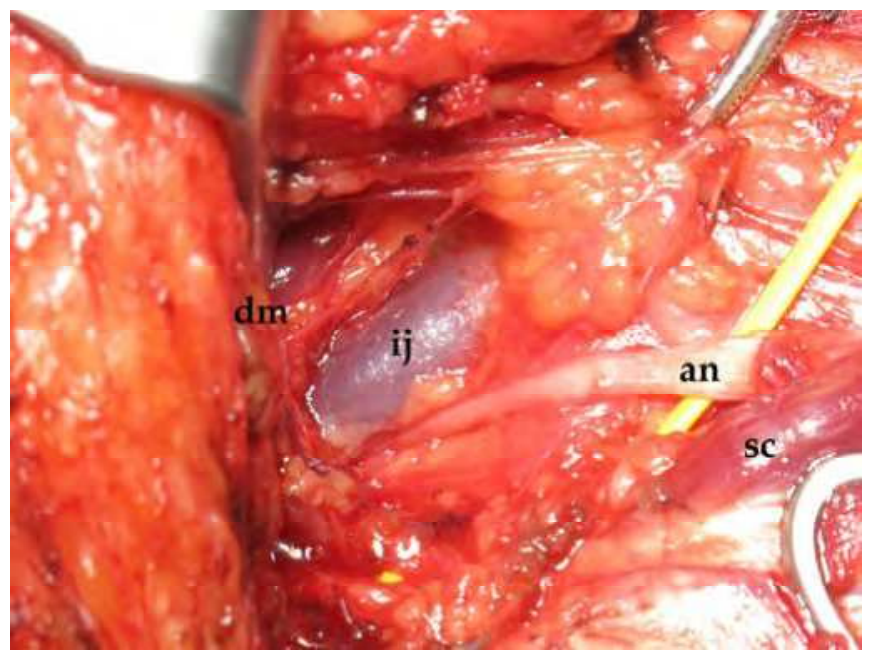

(b)

Fig. 4. Anterior identification of the spinal accessory nerve on the right side of the neck. (a) The spinal accessory nerve (an) is exposed (yellow landmark) between the sternocleidomastoid muscle (sc) and the internal jugular vein (ij). Posterior belly of digastric muscle (dm). (b) Closed view.

\subsection{Spinal accessory nerve maneuver}

The lymph nodes at level $2 \mathrm{~B}$ are located between the spinal accessory nerve and internal jugular vein; this area has an ill-defined boundary and constitutes one of the weak points of the artificial lymph node classification. The surgeon must be especially careful during this step of the operation to avoid missing potentially metastatic lymph nodes. 
At this level, the nerve runs within the "lymphatic container" of the neck, forcing the surgeon to cut across the fibro-fatty tissue. Consequently, the tissue overlying the nerve is divided and the nerve is exposed completely from the sternocleidomastoid muscle to the internal jugular vein. The nerve should be handled carefully, since manipulation alone can lead to long-term dysfunction.

As the dissection approaches the internal jugular vein, the surgeon must be aware of the relationship between these two structures. Usually, the internal jugular vein lies immediately behind the proximal portion of the nerve. On some occasions, however, the nerve may pass behind the vein or even across it.

Once the spinal accessory nerve has been exposed completely, the tissue lying superior and posterior to the nerve must be dissected from the splenius capitis and levator scapulae muscles. The tissue is pulled in an anteroinferior direction toward the spinal accessory nerve.

The deep cervical fascia overlying the splenius capitis and levator scapulae should be preserved. Care must be taken not to injure the internal jugular vein at this level, as control of the subsequent bleeding can be troublesome.

The occipital and sternocleidomastoid arteries are often found at this step of the operation. Most of the time, they are sectioned inadvertently while removing the lymphatic tissue in this area.

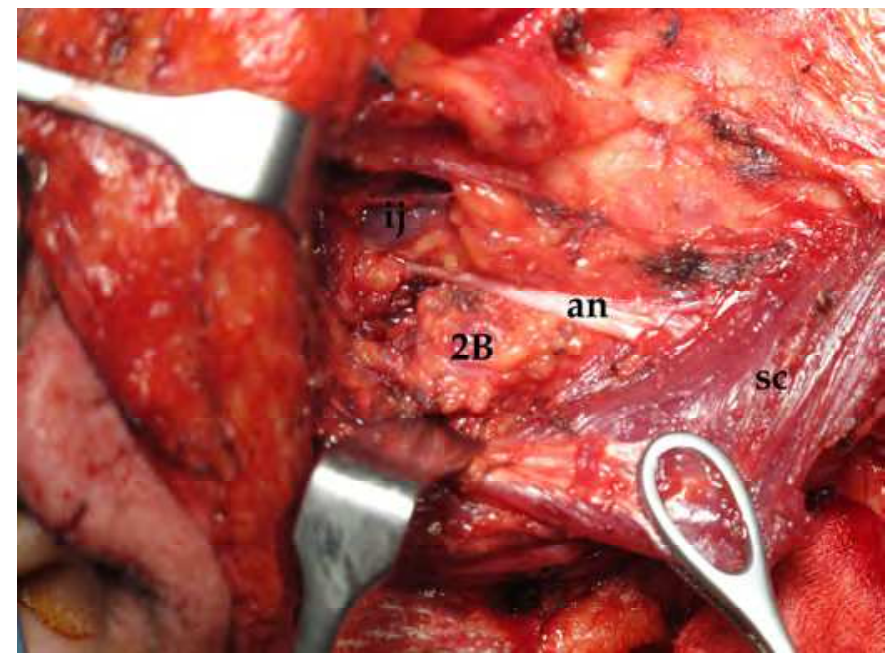

Fig. 5. Spinal accessory nerve maneuver on the right side of the neck. The fibrofatty tissue of the upper spinal accessory region has been dissected from the muscolar floor.

Then, fibro-fatty node-bearing tissue is passed under the spinal accessory nerve and kept in continuity with the reminder of the neck dissection. Osvaldo Suarez referred to this step of the operation as "the spinal accessory maneuver" (Suarez, 1963). 


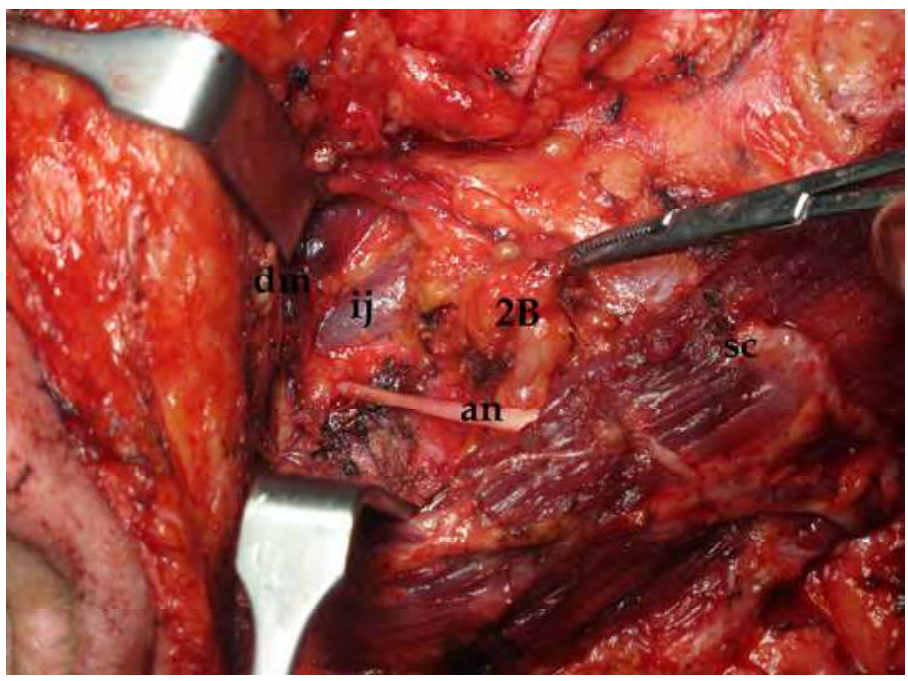

Fig. 6. Spinal accessory nerve maneuver on the right side of the neck. Intraoperative image demonstrating passing node under spinal accessory nerve (an) following dissection level $2 \mathrm{~B}$. Note right angle retraction of posterior belly of digastric muscle $(\mathrm{dm})$ and sternocleidomastoid muscle (sc). Internal jugular vein (ij).

Note that the lymph nodes that are now being removed are located between the spinal accessory nerve and internal jugular vein. This region corresponds to the ill-defined boundary between level 2 and the upper part of level 5 . Therefore, the surgeon must be especially careful during this step of the operation to avoid missing potentially metastatic lymph nodes.

\subsection{Posterior identification of the spinal accessory nerve}

If level 5 is included in the neck dissection, the spinal accessory nerve must be identified at Erb's point. An inferior flap in the subplatysmal plain is elevated to the level of the clavicle. The platysma muscle terminates posteriorly, and in this area, the dissection will be in a subcutaneous plane. The spinal accessory nerve exits the posterior border of the sternocleidomastoid muscle in the posterior neck triangle an average of 1-1.5 cm from the great auricular nerve in a deeper layer above the investing deep fascia (Kazunari et al., 2007; Salgarelli et al., 2009). The spinal accessory nerve leaves the sternocleidomastoid muscle and descends obliquely downward and backward toward the trapezius muscle in a subcutaneous plane. Care must be taken to identify and protect the spinal accessory nerve when a flap is developed here.

Anatomical landmarks define the boundaries of the surgical field in the posterior triangle (level 5). The posterior margin is marked by the anterior edge of the trapezius muscle; the upper boundary is defined by the exit of the spinal accessory nerve toward the trapezius muscle. The inferior limit is located at the level of the clavicle; on the left side, the surgeon must be aware of the variable anatomy of the thoracic duct when approaching the junction of the internal jugular and subclavian veins (levels 4 and 5). The transverse cervical vessels and omohyoid muscle constitute important anatomical landmarks within this area. 


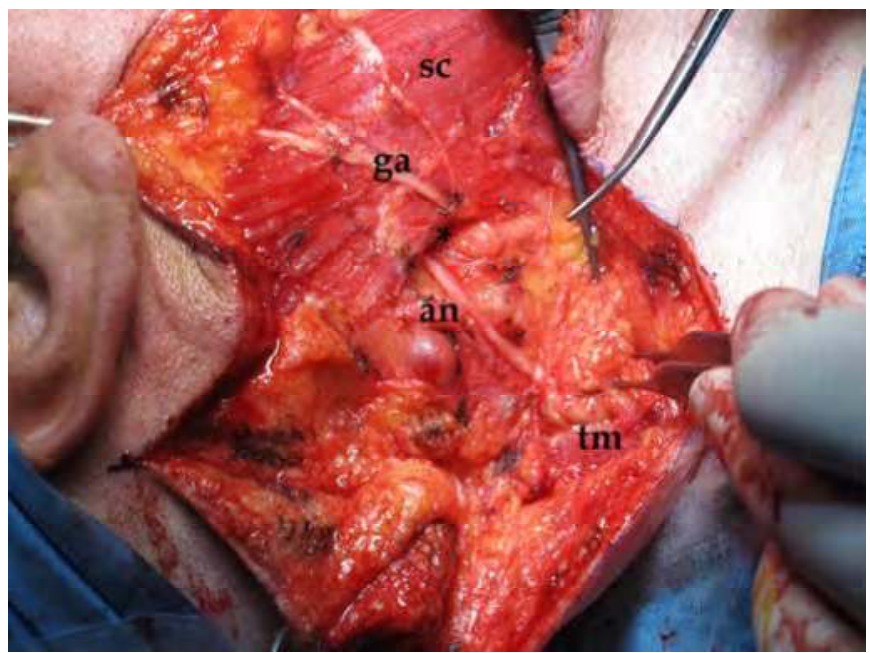

(a)

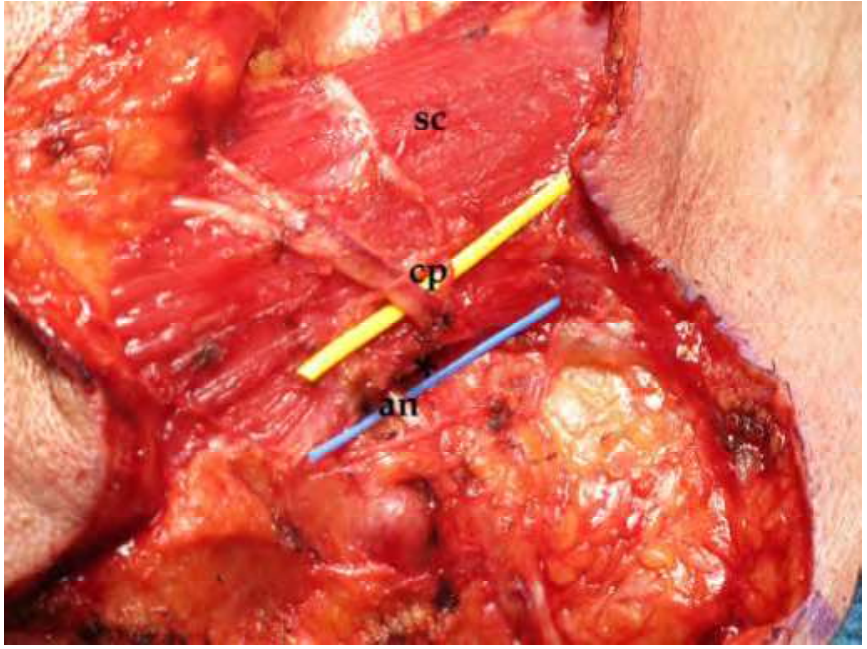

(b)

Fig. 7. Posterior identification of the spinal accessory nerve on the right side of the neck. (a) The spinal accessory nerve (an) is identified as it enters the sternocleidomastoid muscle (sc), usually at the junction of the upper third and lower two thirds of the muscle. Note the Erb's point $\left(^{*}\right)$ and the relations between spinal accessory nerve and the branches of the cervical plexus (great auricular nerve: ga). Trapezius muscle (tm). (b) Closed view: blue landmark on spinal accessory nerve (an) and yellow landmark on cervical plexus (cp).

The operation proceeds while keeping the spinal accessory nerve in view with the removal of the fascia that still covers the posterior border of the sternocleidomastoid muscle. Once completed, this maneuver results in the total release of the muscle from its surrounding fascia. 
Then, the dissection proceeds from the anterior border of the trapezius muscle in a medial direction, including the lymphatic contents of the supraclavicular fossa.

\section{Conclusion}

The preservation of the spinal accessory nerve is essential in neck dissection and guarantees function of the scapula and avoids "sloping shoulder syndrome". The spinal accessory nerve must always be identified at the junction of the upper third and middle third on the medial aspect of the sterocleidomastoid muscle (anterior identification); if the level 5 should be included in the dissection, the nerve must also be identified at Erb's point (posterior identification). Identifying the accessory nerve based on the great auricular nerve should be suitable during surgery, since the great auricular nerve lies in a deeper layer under the investing deep fascia and over the prevertebral fascia. Since the great auricular nerve represents a constantly identifiable landmark, it allows simple and reliable identification of the course of the spinal accessory nerve.

\section{References}

Aramrattana A, Sittitrai P, Harnsiriwattanagit K (2005) Surgical anatomy of the spinal accessory nerve in the posterior triangle of the neck. Asian J Surg 28: 171-3.

Bocca E, Pignataro O. (1967) A conservation technique in radical neck dissection. Ann Oto Rhino Laryngol 76: 975-8.

Bocca E, Pignataro O, Sasaki CT (1980) Functional neck dissection, a description of operative technique. Arch Otolaryngol 106: 524-7.

Bocca E. (1975) Conservative neck dissection. Laryngoscope 85: 1511-5.

Caliot PH, Cabaine P, Bousquet V, Midy D (1989) A contribution to the study of the accessory nerve: surgical implications. Surg Radiol Anat 11: 11-5.

Crile G (1906) Excision of cancer of head and neck. JAMA 47: 1780-6.

Eisele DW, Weymuller EA, Price JC (1991) Spinal accessory nerve preservation during neck dissection. Laryngoscope 101: 433-5.

Kademani D, Dierks EJ. (2005) A straight-line incision for neck dissection: technical note. J Oralmaxillofac Surg 63: 563-3.

Kaji T, Aizawa S, Uemura M, Yasuki K (2001) Establishment of the left right asymmetric innervation of the Lancelot oral region. J Comp Neurol 435: 394-405.

Kazunari S, Shinichi A, Hiroko A, Satoshi M, Koji S, Masatsugu H, Yoshinobu I. (2007) Anatomical study of accessory nerve innervation relating to functional neck dissection. J Oral Maxillofac Surg 65:22-29

Krause HR, Bremerich A, Hermann M (1991) The innervation of the trapezius muscle in connection with radical neck dissection - an anatomical study. J Craniomaxillofac Surg 19: 87-9.

Holmes JD. (2008) Neck dissection: nomenclature, classification and technique. Oral Maxillofacial Surg Clin N Am 20: 459-75.

Leung MKS, Dieu T, Cleland H (2004) Surgical approach to the accessory nerve in the posterior triangle of the neck. Plast Rec Surg 6: 2067-70.

Macfee WF. (1960) Transverse incisions for neck dissection. Ann Surg 151: 279-84.

Martin H, Del Valle B, Ehrlich H, Cahan WG (1951) Neck dissection. Cancer 4: 441-99. 
Medina JE, Lorè JM. (2005) The neck, In: Lorè JM, Medina JE, Anatomic atlas of head and neck surgery, 804, Elsevier, Philadelphia.

Salgarelli AC, Landini B, Bellini P, Multinu A, Consolo U, Collini M. (2009) A simple method of identifying the spinal accessory nerve in modified radical neck dissection: anatomic study and clinical implications for resident training. Oral Maxillofac Surg 13: 69-72.

Soo KC, Guiloff RJ, Oh A, Della Rovere GQ, Westbury G (1986) Innervation of the trapezius muscle: a study in patients undergoing neck dissection. Head Neck Surg 12: 488-95.

Suarez O (1963) El problema de las metastasis linfaticas y alejadas del cacer de laringe e hipofargine. Rev Otorhinolaryngol 23: 83-9.

Symes A, Ellis H (2005) Variations in the surface anatomy of the spinal accessory nerve in the posterior triangle. Surg Radiol Anat 27: 404-8.

Younossi-Hartenstein A, Jones M, Hartenstein V (2001) Embryonic development of the nervous system of the temnocephalid flatworm Craspedella pedum. J Comp Neurol 435: 259-62. 


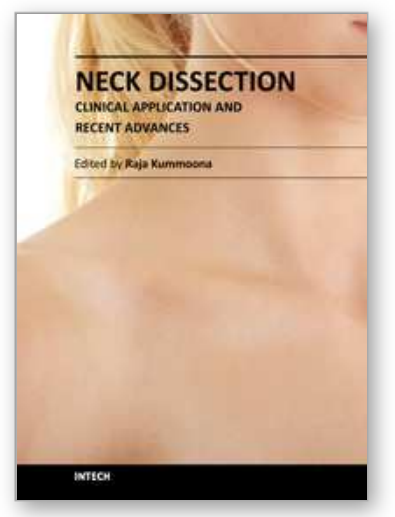

\author{
Neck Dissection - Clinical Application and Recent Advances \\ Edited by Prof. Raja Kummoona
}

ISBN 978-953-51-0104-8

Hard cover, 164 pages

Publisher InTech

Published online 22, February, 2012

Published in print edition February, 2012

Neck Dissection - Clinical Application and Recent Advances is a leading book in neck surgery and represents the recent work and experiences of a number of top international scientists. The book covers all techniques of neck dissection and the most recent advances in neck dissection by advocating better access to all techniques of neck dissection; e.g. Robotic surgery (de Venice) system, a technique for detection of lymph node metastasis by ultra sonography and CT scan, and a technique of therapeutic selective neck dissection in multidisciplinary treatment. This book is essential to any surgeon specializing or practicing neck surgery, including Head Neck Surgeons, Maxillofacial Surgeons, ENT Surgeons, Plastic and Reconstructive Surgeons, Craniofacial Surgeons and also to all postgraduate Medical \& Dental candidates in the field.

\title{
How to reference
}

In order to correctly reference this scholarly work, feel free to copy and paste the following:

Attilio Carlo Salgarelli and Pierantonio Bellini (2012). Surgical Management of the Spinal Nerve in Modified Radical Neck Dissection, Neck Dissection - Clinical Application and Recent Advances, Prof. Raja Kummoona (Ed.), ISBN: 978-953-51-0104-8, InTech, Available from: http://www.intechopen.com/books/neck-dissectionclinical-application-and-recent-advances/surgical-management-of-spinal-nerve-in-modified-radical-neckdissection

\section{INTECH}

open science | open minds

\author{
InTech Europe \\ University Campus STeP Ri \\ Slavka Krautzeka 83/A \\ 51000 Rijeka, Croatia \\ Phone: +385 (51) 770447 \\ Fax: +385 (51) 686166 \\ www.intechopen.com
}

\author{
InTech China \\ Unit 405, Office Block, Hotel Equatorial Shanghai \\ No.65, Yan An Road (West), Shanghai, 200040, China \\ 中国上海市延安西路65号上海国际贵都大饭店办公楼 405 单元 \\ Phone: +86-21-62489820 \\ Fax: +86-21-62489821
}


(C) 2012 The Author(s). Licensee IntechOpen. This is an open access article distributed under the terms of the Creative Commons Attribution 3.0 License, which permits unrestricted use, distribution, and reproduction in any medium, provided the original work is properly cited. 